
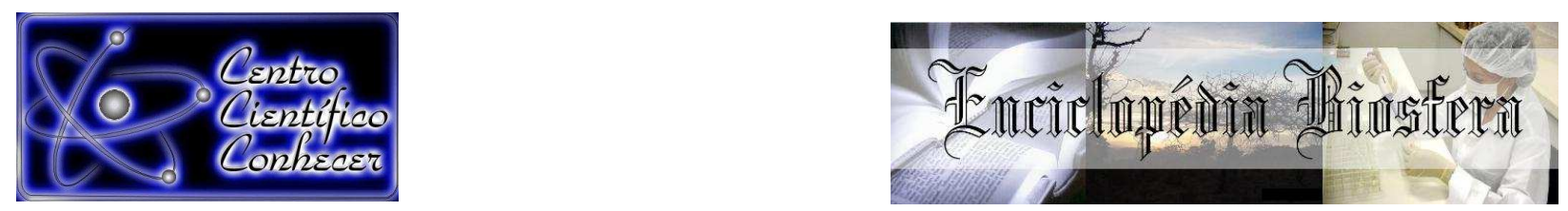

\title{
TÉCNICAS DE SENSORIAMENTO REMOTO NO ÂMBITO DO LICENCIAMENTO DE PLANO DE MANEJO FLORESTAL MADEIREIRO NO ESTADO DE MATO GROSSO
}

Nidoval Rodrigues Silva Junior ${ }^{1}$, Ana Paula Dalla Corte ${ }^{2}$, Bruna Nascimento de Vasconcellos $^{3}$, Carlos Roberto Sanquetta ${ }^{2}$

1 - Engenheiro Florestal, especialista, Secretaria Estadual do Meio Ambiente, Cuiabá, MG - Brasil

2 - Prof. Dr. do Departamento de Engenharia Florestal, Universidade Federal do

Paraná, Curitiba, PR- Brasil

3 - Doutoranda do Programa de Pós Graduação em Engenharia Florestal,

Universidade Federal do Paraná, Curitiba, PR - Brasil - brunaslg@hotmail.com

Recebido em: 08/04/2017 - Aprovado em: 10/06/2017 - Publicado em: 20/06/2017 DOI: 10.18677/EnciBio_2017A97

\begin{abstract}
RESUMO
Brasil possui significativa parte de seu território coberto por vegetação nativa, assegurado por instrumentos legais que confere a floresta como um bem de uso comum e delega ao estado a obrigação de regulamentar e licenciar qualquer atividade neste meio. Diferentemente de áreas intactas, às áreas com intervenções sejam elas por fogo ou exploração seletiva, são impostas algumas restrições de pousio e obrigações de cumprimento de reposição florestal. O objetivo do estudo foi avaliar a dinâmica da vegetação florestal entre os anos de 2008 a 2015 para uma área de 7.259,07 ha localizada no município de Juara - MT. A área de estudo foi delimitada de forma aleatória, de maneira que interceptasse áreas autorizadas pela Secretaria de Estado de Meio Ambiente - SEMA/MT. No estudo utilizou-se imagens dos sensores Thematic Mapper (TM), Operational Land Imager (OLI) e LISS3 dos satélites Landsat 5 e 8 e do satélite IRS-P6, processadas por meio da técnica do cálculo de Índice Normalizado de Diferença de Fração (NDFI) e disponíveis na base de dados da SEMA/MT. Dentro da área de estudo verificou-se que todas as autorizações tiveram sua efetiva exploração dentro do período de validade. Realizaram-se caracterizações das explorações avaliando a disposição da infraestrutura, o respeito aos limites das áreas de preservação permanente e detecção de áreas exploradas sem autorização do órgão ambiental. Neste contexto, verificou-se a importância do sensoriamento remoto para gestão dos planos de manejo florestal madeireiro no estado de Mato Grosso.
\end{abstract}

PALAVRAS-CHAVE: Amazônia legal, exploração seletiva, índice de vegetação. 


\title{
TECHNIQUES OF REMOTE MONITORING IN THE CONTEXT OF THE LICENSING MANAGEMENT FOREST PLAIN OF WOODS BUSINES IN MATO GROSSO STATE
}

\begin{abstract}
Brazil has much of its territory covered by native vegetation, insured by legal instrument that gives everyone the forest as a common use and delegates to the state the obligation to regulatory laws and license any activity in this area. Perhaps for areas with intervention whether by fire or selective exploration, but, there are imposed some restrictions to fallow and obligations for reforestation, which are not imposed on intact areas. The objective of the study is to evaluate the dynamics of forest vegetation between the years 2008 to 2015 to an area of 7259.07 ha located in Juara city (MT). The study area was defined randomly so that intercepting areas authorized by the Secretary of State for the Environment - SEMA / MT. In the study used images from the sensor Thematic Mapper (TM), Operational Land Imager (OLI) and LISS3, from the Landsat 5 and 8 and the IRS-P6 satellite, processed with technical Normalized Difference Fraction Index (NDFI) and available based on Environment Secretary - SEMA-MT. Within the study area it was found that all authorization license had their effective exploitation within the valid period. It where characterized by evaluating the provision of infrastructure for the exploration, respect the limits of the areas of permanent preservation and detection areas explored without authorization by the environmental agency. In this context, there was the importance of remote monitoring for management of forest license plans for woods business in the Mato Grosso State.
\end{abstract}

KEYWORDS: Legal amazon, Selective logging, Vegetation index.

\section{INTRODUÇÃO}

O Brasil apresenta uma expressiva diversidade de ecossistemas florestais, dada a sua extensa área, diversidade de climas e tipos de solos existentes neste território. O desmatamento, principalmente na Amazônia, procede a um alto ritmo, em função de diversas razões, muitas das quais dependem de decisões e políticas governamentais (FEARNSIDE, 2006).

Legislações regulamentam a atividade de Manejo Florestal Sustentável Madeireiro no Brasil, especialmente na Amazônia Legal onde o potencial para esta atividade é alto (RADAM BRASIL, 1980). Nesta região está localizado o estado de Mato Grosso, que representa boa parte de seu território e tem na atividade madeireira representação expressiva de sua economia.

De acordo com a Instrução Normativa $n^{\circ} 005$, de 02/07/2014, que estabelece roteiros específicos para Plano de Manejo Florestal Sustentável - PMFS no estado de Mato Grosso, em áreas onde ocorreram intervenções, sejam elas por exploração seletiva ou por fogo, são impostas algumas restrições à aprovação de projetos quando comparada a uma área intacta (MATO GROSSO, 2014). Ao final de cada exploração, também é necessário ser apresentado junto ao órgão licenciador relatórios baseados nas imagens de satélite que demonstre a efetivação da exploração.

A atividade de Manejo Florestal Sustentável tem como princípio a preservação dos recursos naturais, em especial o recurso florestal que deverá estar disponível no futuro. Os sensores remotos possibilitam aplicações de técnicas de 
processamento digital, as quais os tornam ferramentas ideais na gestão de recursos naturais de ecossistemas tropicais. Assim como o recurso florestal as imagens de sensores orbitais e técnicas de sensoriamento remoto são amplamente utilizadas, em função do melhor aproveitamento de recursos financeiros, operacionais e de tempo (FILGUEIRAS et al., 2016).

As diferentes técnicas de pós-processamento possuem seus objetivos prédefinidos, cujo intuito é destacar informações específicas que dificilmente são vistas quando analisado uma imagem original. Neste contexto, para o estudo da vegetação, destaca-se o uso dos índices de vegetação, juntamente com o modelo de mistura espectral, os quais classificam a cobertura do solo quanto aos níveis de degradação (SOFAN et al., 2016).

Em casos onde há exploração seletiva, a Instrução Normativa $n^{\circ} 005$, de 02/07/2014 exige que no momento do inventário todos os tocos remanescentes sejam identificados por meio de plaqueteamento e localização geográfica (MATO GROSSO, 2014). Desta forma, caso a dinâmica não identifique a exploração de baixo impacto, o serviço in loco tem a função de complementar esta informação. Somado a isto, existe também a obrigação de verificar a necessidade ou não de autuação pelo ilícito, tendo em vista a previsão de prescrição em 5 anos do crime ambiental, de acordo com o Art. $\mathrm{n}^{\circ} 21$ do Decreto 6.514, de 22/07/2008 (BRASIL, 2008). Diante disso, destaca-se a importância da análise temporal das imagens de satélite utilizadas no estudo para a determinação do ano em que ocorreu o ilícito.

A reposição florestal também depende da escala temporal, visto que sua cobrança passou a existir a partir da publicação da Lei complementar $n^{\circ} 233$ de 21/12/2005 (MATO GROSSO, 2005). O inventário dos tocos remanescentes é importante em função da necessidade de avaliar a possível recomposição volumétrica da floresta, bem como a quantificação do volume a ser restituído por meio da reposição florestal. Para avaliar esta recomposição é calculado o volume médio de cada indivíduo atualmente apto para corte e multiplicado pelo número total de tocos, estimando assim o volume ora extraído. A partir deste volume estimado é verificada a recomposição volumétrica baseando no incremento periódico anual de $0,86 \mathrm{~m}^{3} \mathrm{ha}^{-1} \mathrm{ano}^{-1}$, valor instituído pela resolução do Conselho Nacional do Meio Ambiente - CONAMA $n^{\circ}$ 406, de 06/02/2009 (BRASIL, 2009). Caso o tempo decorrido da exploração não tenha sido suficiente para a recomposição volumétrica, o projeto é sobrestado até a data estimada para efetivar a recomposição.

Estudos indicam que o uso de imagens de sensores orbitais é considerado uma ferramenta viável no monitoramento dos impactos causados pela exploração florestal na Amazônia (ASNER et al., 2009). Diante deste contexto, considerando as dimensões do estado de Mato Grosso, existe a necessidade de avaliações anuais dos projetos objeto de licenciamento, bem como a obrigação de monitorar os planos já autorizados e executados, o sensoriamento remoto pode ser uma ferramenta importante no desenvolvimento desta tarefa. O presente estudo objetivou avaliar a dinâmica da vegetação florestal ao longo de 8 anos (2008-2015) por meio de imagens de sensores a bordo de satélites, utilizando técnicas de cálculo de índice de vegetação. 


\section{MATERIAL E MÉTODOS}

\section{Caracterização da área de estudo}

O estudo foi realizado em uma área de 7.259,07 ha, nos limites do município de Juara - MT, no sudoeste da Amazônia Legal (Long.: 57²7'53,634"W e Lat.: $11^{\circ} 40^{\prime} 38,109$ "S), dentro do perímetro da Folha SC 21 JURUENA objeto de estudo no Projeto Radam Brasil. Localiza-se na Bacia Hidrográfica Amazônica, que é a principal da região, e está entre as sub-bacias dos rios Teles Pires e Juruena, à margem esquerda do rio Arinos, um dos principais afluentes do Rio Juruena.

A maior porção da área do estudo é coberta pela Floresta Estacional Semidecidual, onde as estações climáticas são bem definidas, chuvosa e seca e o termo Semidecidual se refere à metade dos indivíduos perderem a folhagem em épocas desfavoráveis (BORGES et al., 2014).

\section{Obtenção dos Dados}

As imagens orbitais utilizadas no estudo estão armazenadas no banco de dados da Secretaria de Estado de Meio Ambiente de Mato Grosso - (SEMA/MT), e foram obtidas por meio do site do Instituto Nacional de Pesquisas Espaciais (INPE) e do site do Serviço Geológico dos Estados Unidos (Science for a Changing World USGS). As respectivas datas e sensores das imagens utilizadas, podem ser observados na Tabela 1.

TABELA 1 - Relação de imagens utilizadas

\begin{tabular}{c|c|c|c}
\hline Data & Sensor & Satélite & Ponto/órbita \\
\hline $\mathbf{1 6 / 0 7 / 2 0 0 8}$ & TM & Landsat 5 & $223 / 068$ \\
\hline $\mathbf{2 0 / 0 8 / 2 0 0 9}$ & TM & Landsat 5 & $223 / 068$ \\
\hline $\mathbf{0 8 / 0 9 / 2 0 1 0}$ & TM & Landsat 5 & $223 / 068$ \\
\hline $\mathbf{2 3 / 0 6 / 2 0 1 1}$ & TM & Landsat 5 & $223 / 068$ \\
\hline $\mathbf{2 7 / 0 7 / 2 0 1 2}$ & LISS3 & IRS-P6 & $318 / 085$ \\
\hline $\mathbf{1 4 / 0 7 / 2 0 1 3}$ & OLI & Landsat 8 & $223 / 068$ \\
\hline $\mathbf{0 1 / 0 7 / 2 0 1 4}$ & OLI & Landsat 8 & $223 / 068$ \\
\hline $\mathbf{1 0 / 0 8 / 2 0 1 5}$ & OLI & Landsat 8 & $223 / 068$ \\
\hline
\end{tabular}

A área de estudo foi demarcada aleatoriamente de forma que interceptasse áreas já autorizadas pela SEMA/MT. Através do banco de dados da secretaria foram consultados os polígonos das Unidades de Produção Anual (UPA's) interceptados, os quais delimitam as áreas autorizadas.

\section{Processamento digital das imagens}

No momento da captura de dados pelos sensores para a formação da base dados de uma imagem de satélite, erros e distorções são passíveis de ocorrer. $\mathrm{O}$ pré-processamento possui principal função de remover ou corrigir os erros e as distorções introduzidos nas imagens devido a erros instrumentais, às interferências da atmosfera e à geometria de imageamento (MENESES \& ALMEIDA, 2012). Após o download das imagens nos sites do INPE e USGS, realizou-se o préprocessamento das mesmas, por meio de calibração radiométrica no software ImgTools e as correções atmosférica e geométrica por meio do software ENVI 4.7. Utilizou-se como ferramenta para realizar a correção atmosférica o algoritmo Fast Line-of-sight Atmospheric of Spectral Hypercubes (FLAASH), presente no 
programa ENVI 4.7, o qual usa o modelo de transferência radiativa Moderate Resolution Atmospheric Radiance and Transmittance Model (MODTRAM). Os parâmetros regionais de cada cena, tais como, coordenada e altitude do terreno no centro da cena, elevação do sol, data e horário de aquisição, altitude do sensor e modelo atmosférico utilizado, compõem a base de dados utilizada no processamento.

A calibração atmosférica se faz necessária tendo em vista a atmosfera atuar como um refletor, adicionando uma radiância extra ao sinal que é detectado pelo sensor e ao mesmo tempo atuar como absorvedor por atenuar a intensidade de energia que ilumina um alvo na superfície.

Realizou-se a correção geométrica, tendo como referência de posicionamento e registros das imagens do estudo foram utilizadas as imagens do sensor Operational Land Imager (OLI) do satélite Landsat-8, as quais já são disponibilizadas no catálogo de imagens do INPE ortorretificadas. Também foram utilizadas imagens do sensor HRV do satélite Spot, as quais estão presentes no Banco de Dados da SEMA/MT. Como pontos de controle (Ground Control Points - GCP's) foram utilizados alvos comuns, tais como rios, ilhas, curvas de estradas, áreas antropizadas, entre outros.

Por meio do programa ImgTools 1.0, a segunda etapa de processamento se baseou no modelo de mistura espectral, onde os dados de reflectância de cada pixel são decompostos nas frações de sombra, solo e vegetação a partir de uma análise de mistura espectral. Estes constituintes puros (endmembers) são esperados em ambientes florestais degradados na Amazônia (SOUZA Jr. et al., 2005). O modelo de mistura espectral é calculado de acordo com a Equação 1.

$$
r_{i}=a^{*} \operatorname{veg}_{i}+b^{*} \text { solo }_{i}+c^{*} \text { sombra }_{i}+e_{i}
$$

Onde $\mathrm{ri}=$ resposta do pixel na banda i; a, b e c proporções de vegetação, solo e sombra (ou água) respectivamente; $v g_{i}=$ resposta espectral do componente vegetação na banda $\mathrm{i}$; solo s $_{\text {a }}$ resposta espectral do componente solo na banda $\mathrm{i}$; sombra $_{i}=$ resposta espectral do componente sombra ou água na banda $\mathrm{i}$; $\mathrm{e}=$ erro na banda $;$; e i = é caracterizado pelas bandas do sensor.

O índice NDFI foi calculado por meio da Equação 2, através das imagens fração geradas a partir do modelo de mistura espectral. O valor do NDFI representa o grau de degradação da floresta, sendo que sua variação está entre -1 e 1. Quanto mais próximo de -1, maior a degradação da floresta. Quanto mais próximo de 1, menor a degradação da floresta. Diante desta variação gradual o NDFI possibilita a avaliar a floresta intacta, passando pelos níveis intermediários de perturbação até o desmate a corte raso (SOFAN, 2016).

$$
N D F I=\frac{\text { VEGnorm }-(N P V+\text { Solos })}{\text { VEGnorm }+(N P V+\text { Solos })}
$$

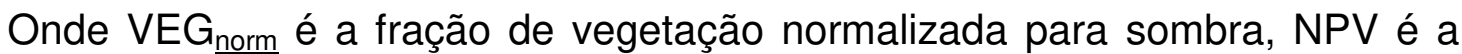
vegetação seca (do inglês non photosynthetic vegetation)(Equação 3).

$$
\text { VEGnorm }=\frac{V E G}{1-\text { Sombra }}
$$




\section{Delimitação das Áreas Exploradas}

Utilizou-se como referência os polígonos das UPA's autorizadas pelo órgão ambiental, sobre os quais, por meio do software ArcGis 10.1, foi feita uma análise visual detectando as áreas exploradas com ou sem autorização. Como base utilizouse imagem do ano anterior à validade da autorização com imagem do período de vigência da mesma, sobre as quais se detectou a diferenciação na resposta espectral pelos índices de vegetação. Além disso, foram delimitadas as áreas de preservação permanente visualizando a imagem na composição colorida e também confrontando com dados Shuttle Radar Topography Mission (SRTM) presentes na base de dados da SEMA/MT.

\section{RESULTADOS E DISCUSSÃO}

A área demarcada para o estudo possui $7.259,0673$ hectares no total. Verificou-se que $1.040,51$ ha já haviam sido abertos a corte raso. Com a identificação e vetorização dos rios, nascentes e áreas úmidas, totalizaram 614,27 ha de Área de Preservação Permanente (APP). Identificou-se um total de 1.205,45 ha de área autorizada à exploração, os quais estão separados em 04 polígonos de Unidade de Produção Anual (UPA).

Como exploração seletiva identificou-se 161,89 ha, sem autorização no ano de 2009. Como área sem deteç̧ão de intervenções, por não apresentar indícios de ocorrência de fogo ou exploração seletiva para os anos do estudo, foi identificado 4.236,95 ha. As informações podem ser verificadas na Tabela 2.

TABELA 2 - Quantificação das áreas que caracterizam a área de estudo entre os de 2008 à 2015.

\begin{tabular}{l|c|c}
\multicolumn{1}{c|}{ Descrição } & Área (ha) & $(\%)$ \\
\hline Área já aberta & $1.040,51$ & 14,33 \\
APP & 614,27 & 8,46 \\
UPA & $1.205,45$ & 16,61 \\
Exploração Seletiva & 161,89 & 2,23 \\
Área sem deteç̧ão de intervenções ${ }^{*}$ & $4.236,95$ & 58,37 \\
Área do Estudo & $7.259,07$ & 100 \\
\hline Orea
\end{tabular}

Onde: APP =Área de Preservação Permanente; UPA = Unidade de Produção Anual. *Período avaliado entre os anos de 2008 a 2015.

A descrição do ano, período de validade e área das autorizações presentes no Banco de Dados da SEMA/MT, interceptadas pela área de estudo, estão presentes na Tabela 3.

TABELA 3 - Relação de autorizações para Manejo Florestal interceptada pela área de estudo com suas respectivas datas de validade e área.

\begin{tabular}{c|ccc}
\hline Ano & Início da validade & Fim da validade & Área (ha) \\
\hline 2008 & $19 / 11 / 2008$ & $18 / 11 / 2013$ & 742,9224 \\
2010 & $22 / 11 / 2010$ & $21 / 01 / 2012$ & 119,4931 \\
2011 & $08 / 08 / 2011$ & $06 / 10 / 2012$ & 52,16146 \\
2013 & $28 / 08 / 2013$ & $28 / 10 / 2014$ & 290,8774 \\
\hline Total & & & $1.205,454$ \\
\hline
\end{tabular}


De acordo com Tabela 3, a autorização do ano de 2008 teve a validade até 18/11/2013. Na Figura 1 observou-se que a exploração ocorreu dentro do período de validade da Autorização para Exploração Florestal (Autex). Em 2008 observouse uma resposta espectral intensa, indicando a cobertura total pela vegetação e em 2009 é possível visualizar as primeiras diferenciações, indicando o início das explorações. No ano de 2010 observou-se que toda a área já havia sido interceptada e em 2011 a área voltou apresentar resposta espectral intensa, indicando a recomposição da cobertura vegetal, restando ainda cicatrizes das estradas e pátios de estocagem.
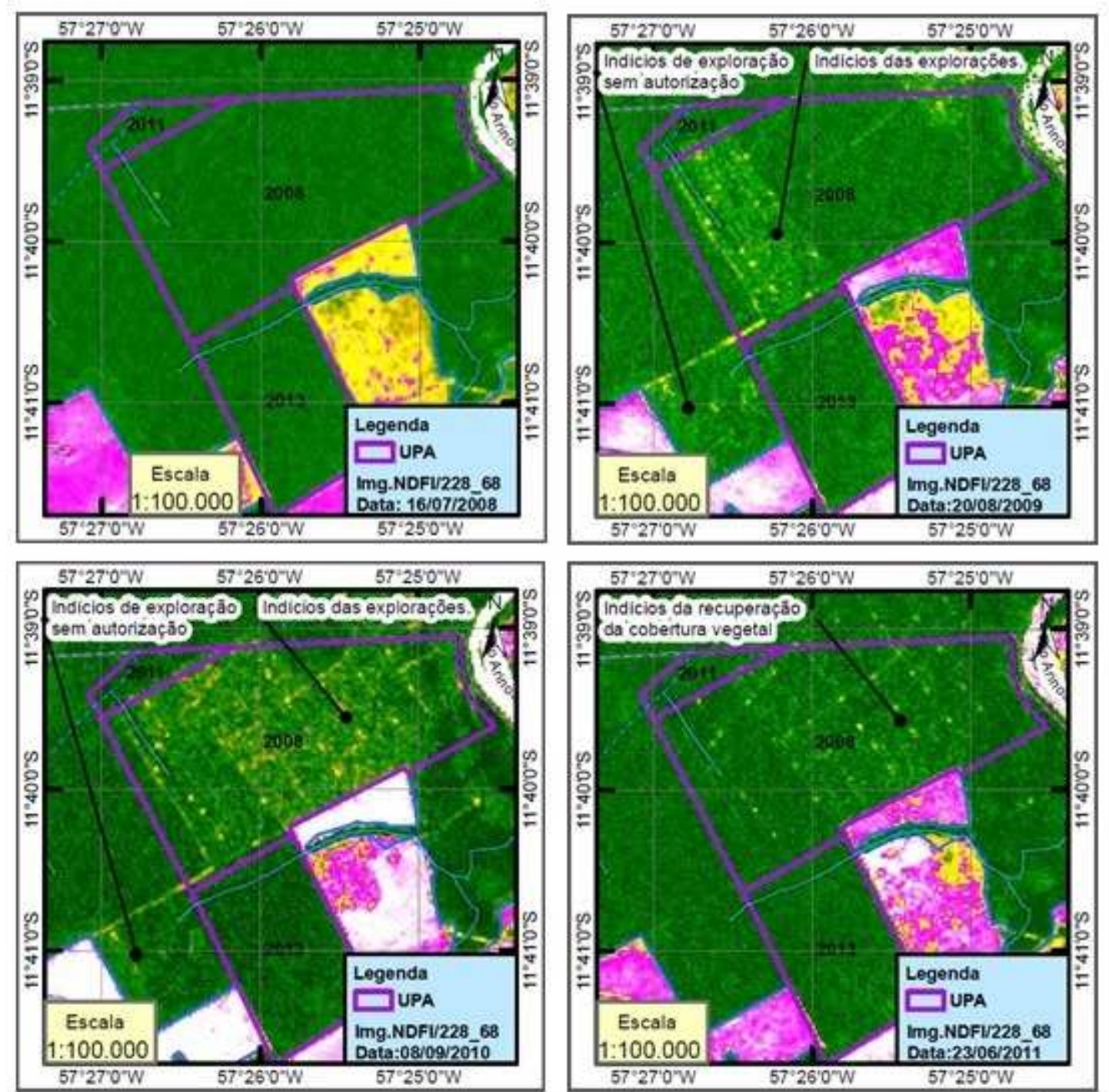

NDFI

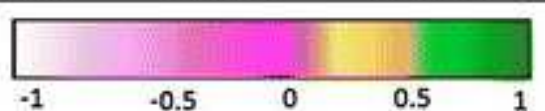

FIGURA 1 - Comparação da resposta espectral da imagem NDFI para os anos de 2008 a 2011, tomando como referência a autorização do ano de 2008.

Vistorias a campo são imprescindíveis para qualificação da execução da exploração em Planos de Manejo. Por meio da imagem do ano de 2011, é possível observar a configuração planejada da infraestrutura, no entanto entre 2009 e 2011 
nota-se uma perturbação generalizada na área, indicando que as técnicas de impacto reduzido na exploração foram pouco utilizadas. Este indício promove ao órgão gestor um alerta para monitorar esta área através de vistorias a campo, onde se realiza a conferência dos indicadores de exploração de impacto reduzido.

Destaca-se na Figura 1, a área identificada com indícios de exploração seletiva, porém sem autorização na Base da SEMA/MT. Esta é uma informação cervical no processo de licenciamento, tendo em vista a possibilidade de identificação dos indícios tanto em quantidade de área como o ano do ocorrido. Estes dados norteiam as providências do estado quanto à autuação pelo ilícito, da possibilidade ou não de autorizar Plano de Manejo para a área, bem como a cobrança de reposição florestal.

Considerando o ano de 2009 como data do ocorrido, atualmente não caberia o auto de infração, pelo fato de já terem decorrido cinco anos, conforme preconiza o Art. 21 do Decreto 6.514 de 22/07/2008 (BRASIL, 2008). No momento do licenciamento da propriedade a qual pertence a área explorada, a reposição florestal, instituída a pela Lei complementar $n^{\circ} 233$ de 21/12/2005 através de seu art. $n^{\circ} 46$, deverá ser cumprida, pois esta obrigação não prescreve (MATO GROSSO, 2005).

De acordo com Instrução Normativa $n^{\circ}$ 005, de 02/07/2014, em um eventual requerimento de Plano de Manejo para esta área, deverá ser apresentado o inventário de $100 \%$ dos tocos remanescentes da exploração (MATO GROSSO, 2014). Com este inventário estima-se o volume médio extraído, baseado no volume médio dos indivíduos remanescentes aptos à extração. Verifica-se o tempo de pousio necessário para recomposição volumétrica tomando $0,86 \mathrm{~m}^{3} / \mathrm{ha} /$ ano como fator de incremento, valor este definido pelo art. 3 da Resolução do CONAMA $n^{\circ}$ 406, de 02/02/2009 (BRASIL, 2009). Com o volume médio estimado cobra-se a reposição florestal e pelo tempo decorrido verifica-se se já ocorreu recomposição volumétrica, caso o tempo não tenha sido suficiente não se expede a autorização.

Apesar de as legislações permitirem autorizar Planos de Manejo em área já explorada seletivamente sem autorização, desde que atendendo alguns requisitos, ASNER et al. (2009) apontam uma visão mais técnica do caso. A exploração ilegal interfere diretamente na ecologia da Floresta, além de realizar a atividade sem recolher impostos ao estado e dispondo de mão de obra informal. Maiores informações desta área devem ser monitoradas, visto que a partir da exploração seletiva a floresta passa a ter maior vulnerabilidade à ocorrência de incêndio (SOUZA et al., 2005; ASNER et al., 2009). Como agravante esta área conta com áreas de atividade agropecuária em seu entorno, onde é comum o uso de fogo para manutenção e limpeza das mesmas.

$\mathrm{Na}$ Figura 2 constatou-se que as explorações também ocorreram dentro do prazo correspondente à validade das autorizações do ano de 2010 e 2013. Destacase a imagem do ano de 2012 por ter sido obtida pelo satélite IRS-P6, o qual possui a bordo o sensor LISS3. Devido à falta de imagens dos satélites Landsat 5 e 7 a partir de novembro de 2011 e a inoperância à época do satélite Landsat 8, MONDAL et al. (2014) testaram alguns índices de vegetação utilizando as imagens do satélite IRSP6, sensor LISS3. Este sensor não possui as bandas 1 e 7 como os sensores Landsat, portanto possui menor resolução espectral, no entanto os autores consideraram o sensor LISS3 uma ferramenta viável, pois as imagens processadas permitem a detecção de alvos como estradas, danos no dossel e pequenas clareiras. 
Tanto para o ano de 2012 quanto 2014 nota-se a construção planejada da infraestrutura. Distribuídos em uma configuração uniforme destacam-se os pátios de estocagem pelas tonalidades mais claras e de forma semelhante também a distância entre as estradas, girando em torno de 400 metros, atendendo as recomendações dos normativos e configurando uma ação planejada.
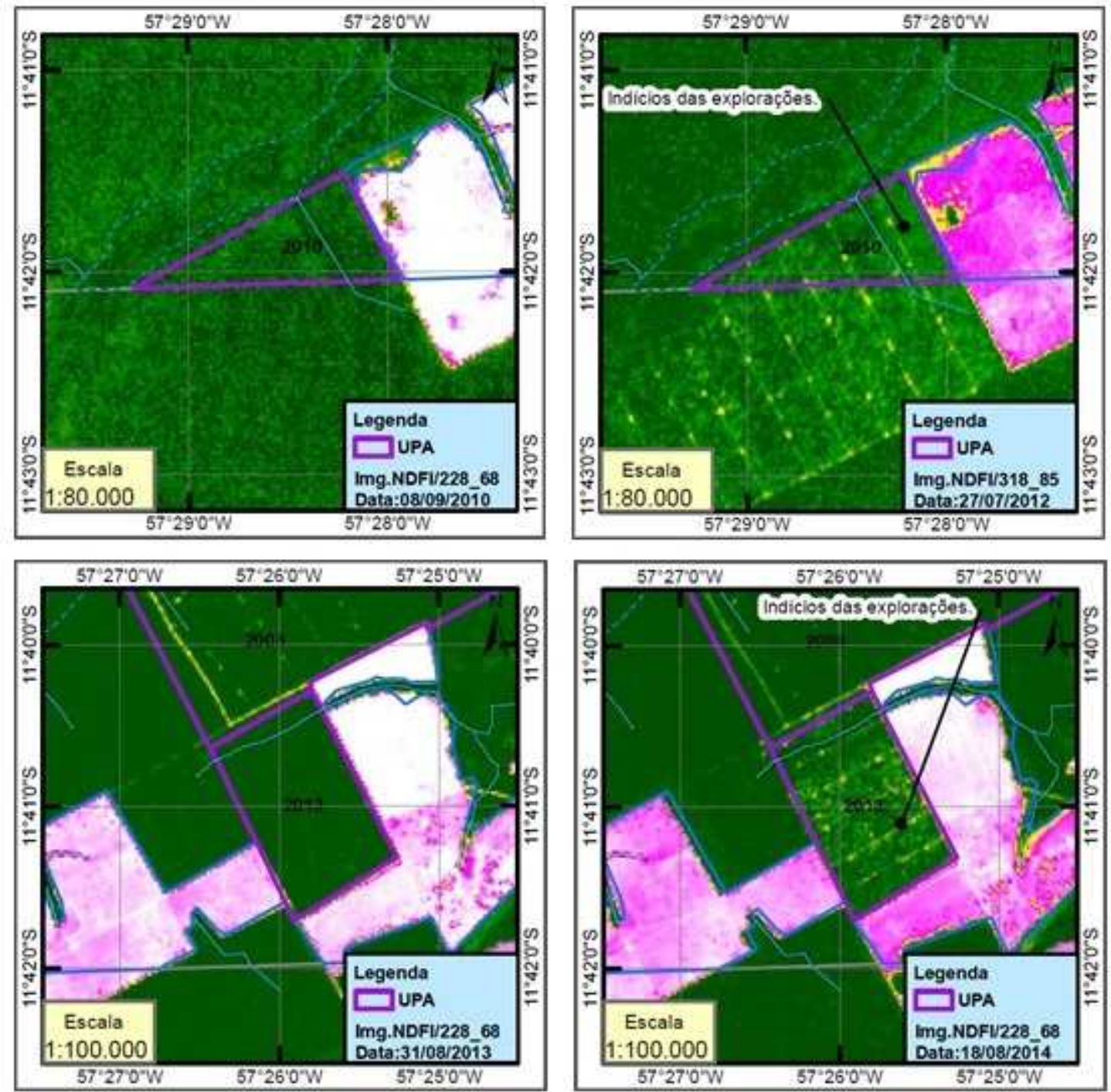

NDFI

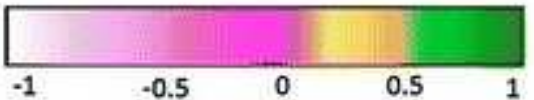

FIGURA 2 - Comparação da resposta espectral da imagem NDFI do ano de 2010 a 2014, tomando como referência as autorizações dos anos de 2010 e 2013.

Além disso, na Figura 3 é apresentada a caracterização geral da área de estudo, com a imagem de 2015 onde se observou a predominância da recomposição da vegetação das áreas exploradas. Tanto na Figura 2 quanto na 3 , foi observado que a área de estudo possui grande representatividade por remanescente de floresta nativa com potencial para novos Planos de Manejo. A baixa densidade de hidrografia somada à topografia plana da área indica a facilidade 
em planejar a construção de estradas e pátios de estocagem, os quais representam as principais infraestruturas de um Plano de Manejo Madeireiro.

Com exceção da UPA - 2008 todas as autorizações tiveram sua validade efetiva de 12 meses, renováveis por mais 12, como é o caso da UPA - 2013, desde que devidamente justificado, analisado e autorizado pelo órgão ambiental. Observase que o período da autorização compreende 14 meses, no entanto no estado de Mato Grosso é instituído pelo art. $1^{\circ}$ da Resolução $n^{\circ} 001$, de 01/07/2013 da Câmara Técnica Florestal, o período restritivo que correspondente aos meses de fevereiro e março, onde não é permitida atividade exploratória dentro da Unidade de Produção Anual devido ao período chuvoso, portanto o período efetivo autorizado a explorar foi de 12 meses (MATO GROSSO, 2013).

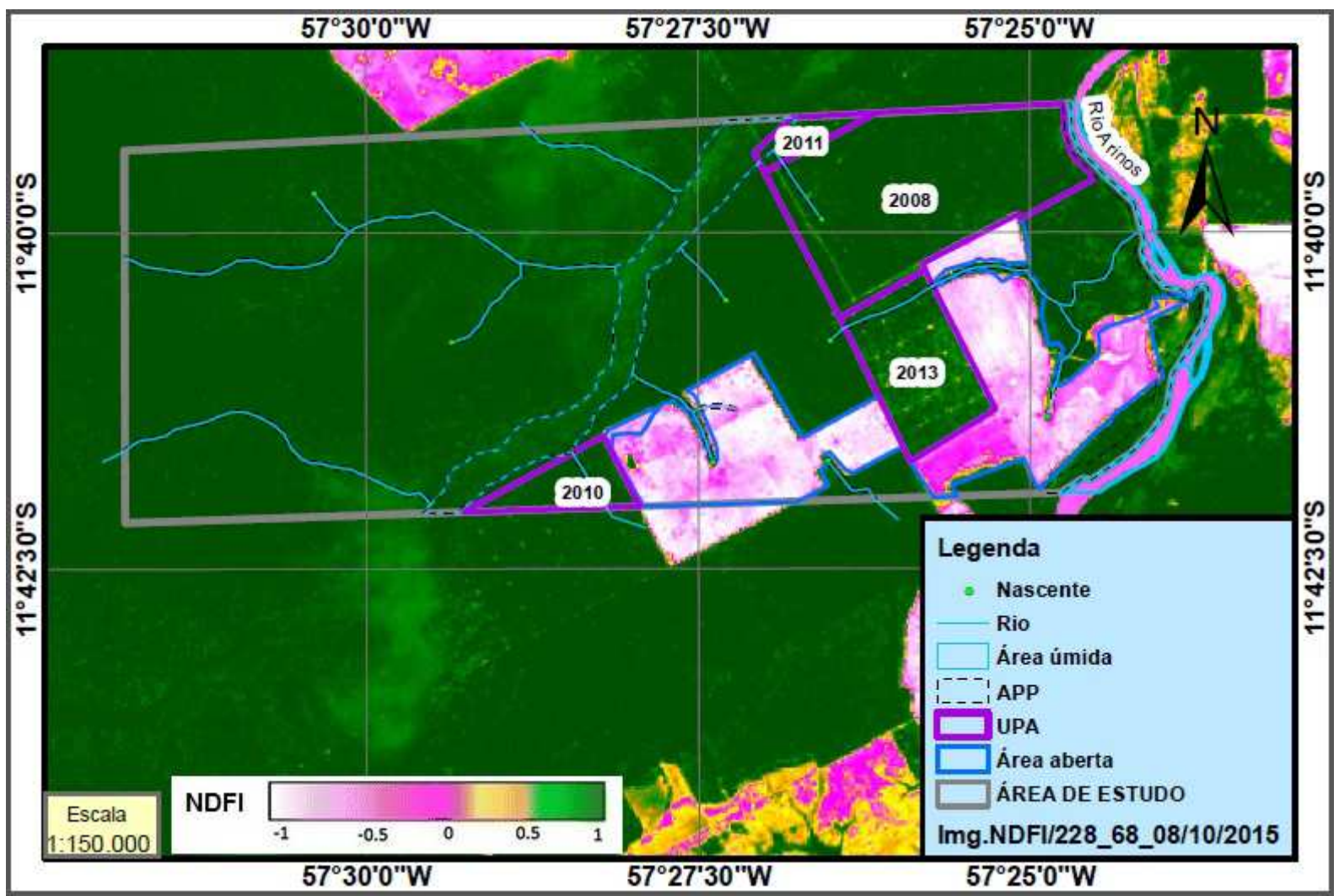

FIGURA 3 - Perímetro com caracterização geral da área de estudo sobrepondo a imagem NDFI do ano de 2015.

Há de se considerar que o presente estudo foi realizado em uma área reduzida quando comparado à área em potencial de Manejo Florestal no estado de Mato Grosso. Considerando esta grande dimensão do Estado, bem como o alto número de projeto a se monitorar, faz-se necessário o uso de ferramentas automatizadas na realização desta tarefa.

A classificação automática possui grande vantagem em agilizar a segmentação das componentes da imagem fração, sendo muito utilizada em estudos de grandes áreas (VASCONCELOS \& NOVO, 2004). Como ferramenta primária ela indica os locais de maior intensidade de exploração, os quais seriam filtrados e encaminhados para análises mais apuradas, visto que as técnicas de classificação automática demandam de auditagem pós-processamento para correção dos erros. Este procedimento de auditagem já é adotado pelo INPE no 
Programa Brasileiro de Desmatamento da Amazônia, conforme cita MULLER et al. (2016).

Em um estudo realizado na região do reservatório de Tucuruí - PA, aplicando - modelo linear de mistura espectral VASCONCELOS \& NOVO (2004), segmentaram as componentes vegetação, solo e sombra, onde foi possível coletar amostras e realizar a classificação automática supervisionada. Ao final concluíram que a segmentação das imagens fração do modelo linear de mistura se mostrou eficiente na escolha das melhores amostras de todas as classes para posterior treino do algoritmo classificador.

SOUZA JR. (2005) apresenta em seu estudo os avanços do sensoriamento remoto para o monitoramento da exploração madeireira na Amazônia, revisando por meio de comparação os métodos existentes em suas vantagens e desvantagens e discutindo o potencial dos diferentes sensores para este fim. O melhor custo benefício foi encontrado no uso de sensores de resolução espacial moderada, embora os sensores de alta resolução apresentar maior precisão, a aquisição destas imagens tem custo alto e não há técnicas automáticas desenvolvidas para o processamento deste tipo de dado. Por fim conclui que o sensoriamento remoto será fundamental para o controle das concessões florestais na Amazônia.

\section{CONCLUSÕES}

Através das imagens processadas pelo NDFI, foi possível observar o período de efetiva exploração, comparando a diferença entre as imagens de cada ano e confrontando com o período de validade da autorização. Logo, a avaliação da dinâmica da vegetação florestal é uma técnica que ajuda tanto nas fases que antecedem o licenciamento, quanto nas fases posteriores a autorização.

Diante da alta quantidade de processos a serem acompanhados pelo órgão ambiental, o sensoriamento remoto permite direcionar o monitoramento para locais que requerem melhor atenção.

\section{REFERÊNCIAS}

ASNER, G. P.; KELLER, M.; LENTINI, M.; MERRY, F.; SOUZA JR. C. Selective logging and its relation to deforestation. Amazonia ang global change. V.186, Washington D.C: American Geophysical Union, p.25-42, 2009.

BAPTISTA, G. M. DE M.; NETTO, J. DA S. M.; MENESES, P. R. Análise de métodos de correção atmosférica na determinação do índice espectral RCGB dos solos tropicais por meio dos dados do sensor hiper espectral aviris (Airborne Visible/Infra Redlmaging Spectrometer). Disponível em: http://www.geocities.ws/gustavombaptista/pesquisas/pro003.pdf. Acesso em: 07/11/2016.

BRASIL. Constituição da República Federativa do Brasil, de 05 de outubro de 1988. Texto constitucional promulgado em 5 de outubro de 1988, com as alterações adotadas pelas Emendas Constitucionais nos 1/1992 a 68/2011, pelo Decreto Legislativo no 186/2008 e pelas Emendas Constitucionais de Revisão nos 1 a 6/1994 - 35ª Edição. Diário Oficial da União, Brasília, DF, n. 191-A, 05 out. 1988. Seção 1, p. 1. 
BRASIL. Decreto $n^{\circ}$ 6.514, de 22 de Julho de 2008. Dispõe sobre as infrações e sanções administrativas ao meio ambiente, estabelece o processo administrativo federal para apuração destas infrações, e dá outras providências. Diário Oficial da União, Brasília, DF, n. 140, 23 jul. 2008. Seção 1, p. 1.

BRASIL. Resolução n 406 - conselho Nacional do Meio ambiente - Conama, de 02 de fevereiro de 2009. Estabelece parâmetros técnicos a serem adotados na elaboração, apresentação, avaliação técnica e execução de Plano de Manejo Florestal Sustentável- PMFS com fins madeireiros, para florestas nativas e suas formas de sucessão no bioma Amazônia. Diário Oficial da União, Brasília, DF, n. 26, 06 fev. 2009. Seção 1, p. 100.

BERNARDO, N.; WATANABE, F.; RODRIGUES, T.; ENNER, A. Atmospheric correction issues for retrieving total suspended matter concentrations in inland waters using OLI/Landsat 8 image. Advances in Space Research, p.1-35, 2017. DOI: $\quad$ http://dx.doi.org/10.1016/j.asr.2017.02.017, Disponível em: http://www.sciencedirect.com/science/article/pii/S027311771730114X

BORGES, H. B. N.; SILVEIRA, E. A.; VENDRAMIN, L. N. Flora arbórea de Mato Grosso: tipologias vegetais e suas espécies. Cuiabá - MT, Entrelinhas, 2014.

FEARNSIDE, P.M. Desmatamento na Amazônia: dinâmica, impactos e controle. Acta Amazonica, v.36, p.395-400, 2006.

FILGUEIRAS, R.; CARVALHO, T.M.; LANDIM, P.M.B.; ZIMBACK, C.R.L. Classificação de usos da terra por análise discriminante multigrupos. Geociências, v.35, n.2, p.255-266, 2016. Disponível em: http://www.revistageociencias.com.br/geociencias-arquivos/35/volume35_2_files/352-artigo-08.pdf

MATO GROSSO. Lei Complementar $n^{\circ}$ 233, de 21 de dezembro de 2005. Dispõe sobre a Política Florestal do Estado de Mato Grosso e da outras providências. Diário Oficial do Estado de Mato Grosso, Cuiabá, MT, n. 24.257, 21 dez. 2005. p. 8.

MATO GROSSO. Resolução n 001 - Câmara Técnica Florestal, de 02 de julho DE 2013. Dispõe sobre o período restritivo de corte, derrubada, arraste e transporte nos planos de manejo florestal com rendimento sustentável (PMFS) aprovados no Bioma Floresta no Estado De Mato Grosso. Diário Oficial do Estado de Mato Grosso, Cuiabá, MT, n. 26.078, 03 jul. p. 26, 2013,

MATO GROSSO. Instrução Normativa $n^{\circ}$ 005, de 02 de julho de 2014. Estabelece roteiros específicos para Plano de Manejo Florestal Sustentável - PMFS Madeireiro. Diário Oficial do Estado de Mato Grosso, Cuiabá, MT, n. 26.321, 02 jul. 2014. p. 18.

MENESES, P. R.; ALMEIDA, T. DE; Introdução ao processamento de imagens de sensoriamento remoto. Brasília, 2012.

MONDAL, S.; JEGANATHAN, C.; SINHA, N.K.; RAJAN, H.; ROY, T.; KUMAR, P. Extraction seasonal cropping patterns using multi-temporal vegetation indices from ENCICLOPÉDIA BIOSFERA, Centro Científico Conhecer - Goiânia, v.14 n.25; p.1196 2017 
IRS LISS-III data in Muzaffarpur District of Bihar, India. The Egyptin Journal of Remote Sensing and Space Sciences, v.17, p. 123-134, 2014. DOI: http://dx.doi.org/10.1016/j.ejrs.2014.09.002, Disponível em: http://ac.elscdn.com/S111098231400026X/1-s2.0-S111098231400026Xmain.pdf?_tid=dd73519a-f9d1-11e6-ba12-

00000aacb35e\&acdnat $=1487859224 \_4 b 55 c 8 c 9 c a 12139 b 872 d 614 \mathrm{fcd} 9 f 878 f$

MULLER, H.; GRIFFITHS, P.; HOSTERT, P.; Long term deforestation dynamics in the Brazilian Amazon-Uncovering historic frontier development along the CuiabáSantarém highway. International Journal of Applied Earth Observation And Geoinformation, $\quad$ v.44, $\quad$ p.61-69, $2016 . \quad$ DOI: http://dx.doi.org/10.1016/j.ag.2015.07.005. Disponível em: http://www.sciencedirect.com/science/article/pii/S030324341530009X

PERES, C. A.; BARLOW, J.; LAURANCE, W. F.Detecting anthropogenic disturbance in tropical forests. Trends in ecology and evolution., v. 21, n. 05, maio de 2016.

RADAM BRASIL. Projeto RADAMBRASIL: 1973-1983, Levantamento de Recursos Naturais. Ministério das Minas e Energia, Departamento Nacional de Produção Mineral (DNPM), Rio de Janeiro, 1980. v. 20.

SOFAN, P.; VETRITA, Y.; YULIANTO, F.; KHOMARUDIN, M.R. Multi-temporal remote sensing data and spectral indices analysis for detection tropical rainforest degradation: case study in Kapuas Hulu and Sintang districts, West Kalimantan, Indonesia. Natural Hazards, v. 80, p.1279-1301, 2016

SOUZA JR, C. M.; ROBERTS, D. A.; COCHRANE, M.A. Combining spectral and spatial information to map canopy damage from selective logging and forest fires. Remote Sensingof Environment, Belém, n. 98, p. 329- 343, 2005.

VASCONCELOS, C. H.; NOVO, E. M. L. DE M. Mapeamento do uso e cobertura da terra a partir da segmentação e classificação de imagens - fração solo, sombra e vegetação derivadas do modelo linear de mistura aplicado a dados do sensor TM/Landsat5, na região do reservatório de Tucuruí - PA. Acta Amazônica. São José dos Campos-SP, v. 34(3), p. 487 - 493, 2004. 